\title{
A Fuzzy-Rough Set Approach for Evaluating the Microfinance Performance of Bank
}

\author{
Qiguang Zhang ${ }^{\mathrm{a}, *}$ and Chong $\mathrm{Wu}^{\mathrm{b}}$ \\ School of Management, Harbin Institute of Technology, Haerbin 150001, China \\ zhangqiguang1972@qq.com, ${ }^{b} 12520679 @ q q . c o m$ \\ *zhangqiguang1972@qq.com
}

\begin{abstract}
Microfinance has entered the phase of rapid development and it has become one of the most important businesses in commercial banks. This study set up an evaluation system based on the balanced scorecard and used the fuzzy-rough set approach to evaluate the microfinance performance. Firstly, this study designed the performance evaluation system from five dimensions according to the principals of balanced scorecard. It needs an objective and scientific method to allocate the weight of indicators of bank's microfinance evaluation system. How to overcome the fuzziness problem and lack of objectivity becomes the point of the research. Then this study used the fuzzy comprehensive evaluation method which is based on the rough set to determine the weight of indicators. Finally this study made an empirical study by using above method and got the fuzzy evaluation results. The effectiveness and practicability of the method were verified by the empirical results.
\end{abstract}

Keywords: Rough set, fuzzy, performance evaluation, balanced scorecard, microfinance

\section{Introduction}

After the commercialization of Chinese microfinance in 2005, microfinance entered a high-speed development stage. The large-scale commercial banks tend to offer loans to large enterprises who have good credit and complete accounting records and they are not willing to offer loans to small and micro businesses who have incomplete accounting records and poor credit. Although the amount small and micro businesses need is small, the number of these businesses is very large and the market prospect is enormous. Now, Microfinance is regarded as an opportunity to expand by small and medium-sized banks.

Weight reflects the relative importance of all indicators which are used to evaluate performance. However, how to determine the weights will affect the evaluation result. According the source of data, we can divide the weight determining methods into two categories which are subjective weighting methods and objective weighting method. Delphi and AHP are subjective weighting methods, mean variance method and principal component analysis method are subjective methods. More or less, these methods are affected by the subjective preference and the evaluation result's objectivity and authenticity will be affected by the illogical allocation of indicators' weights. What's more, it is difficult to use theory of probability and statistics to analyze small sample information and object it is own has uncertainty.

Different experts sometimes get different weights, even totally opposite result. Therefore, illogical allocation will make the evaluation not objective. The main

${ }^{*}$ Corresponding Author 
evaluation methods used in foreign commercial banks are: CAMEL to evaluate and rank the performance of Bank of Nigeria [1]; CAMEL to contrast the performance of Egypt Alexandria Bank, before and after privatization and found that the performance has obviously improved after privatization [2]; BSC can improve financial performance and the performance of BSC is much better than traditional performance model [3]; BSC to evaluate the bank's performance and determined the weights by using ANP model [4]; DEA to evaluate the efficiency of branches of Czech [5]; DEA and goal programming to evaluate the performance of a Greek bank [6]; DEA to evaluate the efficiency of Bangladesh online bank from 2001 to 2007 [7]; two basic DEA models to analyze the efficiency of bank of Nepal from 2007 to 2011 and found that the efficiency has been improved generally [8]; evaluating the customer service performance of Mercantile Bank Limited [9]; using the evaluation system which included customer satisfaction, employees' review and indicators of operating evaluated bank's performance.

This paper establishes a five dimension performance evaluation system for microfinance of commercial bank. It needs more objective and scientific method to determine indicators' weights. Therefore, how to overcome the problem of fuzziness and lack of objective becomes the target and point of the research. We need experts' experience and knowledge to help us to determine the weight; however we should also try to avoid the human factor when determining the weight, and to make the result more objective. To solve these problems, this paper designed the fuzzy comprehensive evaluation method which is based on the rough set, that was, fuzzy mathematics and rough set were used in the empirical analysis of performance of commercial bank microfinance to get a better evaluation results. It introduced the concept of information volume into the information system of rough set. This paper used the information volume of the knowledge to define the importance of attributes and the theory of rough set to determine the objective weight of indicators, and then built the fuzzy comprehensive performance evaluation model. Combining the fuzzy system and rough set theory can have both advantages of the two and the weight of indicators can be more objective.

\section{Materials and Methods}

The principle of this method is that: first, determine the objects' rough set and evaluation set; second, determine the weight and membership vector of each indicator and build the fuzz evaluation matrix; third, get the fuzzy evaluation result by using fuzzy operation and normalization to process the matrix and factors' weight vectors. The specific steps are followed:

\subsection{Build the Rough Set and Evaluation Set}

Rough set theory converts the determination of weight into evaluation of the importance of the attributes of the rough set. By building the relational data model and characterization of the attributes value, the knowledge system is built. We analyze the support degree and the importance of objects under the data driven, we can calculate the weights of the comprehensive evaluation model.

First, determine factor domain $\mathrm{U}$ and evaluation grade domain $V$. Factor domain

$U=\left\{U_{1}, U_{2}, \ldots, U_{n}\right\}$

That is the set of $\mathrm{n}$ indicators.

$S=(U, A, V, f)$ is a knowledge expression system. $U$ is the finite nonempty set of objects. It is called domain $U=\left\{x_{1}, x_{2}, \Lambda, x_{n}\right\}, A=C \cup D$ is the finite nonempty 
set of attributes, $C \cap D=\Phi$, subset $C$ and $D$ are subset of condition attributes and result attributes; $V=\gamma V_{a}$ is the set of attribute value, $V_{a}$ means the scope of the attribute $a \in A$, that is range of attribute $a, f: U \times A \rightarrow V$ is a information function which allocates the attribute value of each $x$ in $U$.

Evaluation grade domain

$V=\left\{V_{1}, V_{2}, \ldots, V_{m}\right\}$,

This is the evaluation grade set, and it has $\mathrm{m}$ grades in total which is generally divided into 3 to 5 grades.

If evaluating the indicator $j$ of dimension $i$, then the membership degree is $f_{i j k}(i=1,2, \ldots, N ; j=1,2, \ldots, n ; k=1,2, \ldots, m)$, and the membership matrix is:

$f=\left[\begin{array}{ccc}f_{i_{1} 1} & \cdots & f_{i_{1} m} \\ \vdots & \ddots & \vdots \\ f_{i_{n} 1} & \cdots & f_{i_{n} m}\end{array}\right] \quad i=1,2, \ldots, N$

Assuming that $S=(U, A, V, f)$ is a information system, the definition of importance of attribute $a \in A$ in $A$ is:

$\operatorname{Sig}_{A-\{a\}}(a)=I(A)-A(A-\{a\})$

When $A=\{a\}, \operatorname{Sig}(a)$ stands for $\operatorname{Sig}_{\Phi}(a)$ :

$\operatorname{Sig}(a)=\operatorname{Sig}_{\Phi}(a)=I(a)-I(\Phi)=I(\{a\})$

In above, $U /$ ind $(\Phi)=\{U\}, I(\Phi)=0$. So the importance of attribute $a \in A$ in $A$ is evaluated by the change of information volume after $a$ is deleted in $A$.

\subsection{Determine the Comprehensive Weight of $W_{i}$}

Suppose $S=(U, A, V, f)$ is an information system, the weight of attribute $a_{i} \in A\left\{a_{1}, a_{2}, \Lambda, a_{n}\right\}$ is:

$$
w_{i}=\frac{\operatorname{Sig}_{A-\left\{a_{i}\right\}}\left(a_{i}\right)}{\sum_{j=1}^{n} \operatorname{Sig}_{A-\left\{a_{j}\right\}}\left(a_{j}\right)}=\frac{I(A)-I\left(A-\left\{a_{i}\right\}\right)}{n I(A)-\sum_{j=1}^{n} I\left(A-\left\{a_{j}\right\}\right)}
$$

\subsection{Fuzzy Comprehensive Evaluation}

Evaluate the second level indicators of each first level indicator, according to the evaluation grade domain. This evaluation is fuzzy mapping. The fuzzy mapping of set $\Omega_{i}$ to set $\mathrm{V}$ is $f: \Omega_{i} \rightarrow V$. We can get the fuzzy membership matrix of second level indicators.

Fuzzy membership matrix of second level indicators:

$g_{i}=\left[\left(f_{i j k}, p_{i j k}\right)_{n \times k}\right]=\left[\begin{array}{ccc}\left(f_{i 11}, p_{i 11}\right) & \cdots & \left(f_{i 1 k}, p_{i 1 k}\right) \\ \vdots & \ddots & \vdots \\ \left(f_{i n 1}, p_{i 11}\right) & \cdots & \left(f_{i n k}, p_{i n k}\right)\end{array}\right]_{n \times k}$ 
$f_{i j k}$ stands for the membership of indicator $X_{i j}$ to evaluation grade $\mathrm{k}, p_{i j k}$ stands for the dot degree of $f_{i j k}$.

$$
p_{i j}=\frac{\sum_{k=1}^{h} p_{i j k}}{h}
$$

$H$ is the number of experts, $p_{i j k}$ means the extent of complete information when expert $k$ gives the evaluation result $j$ to indicator $i, p_{i j k}$ belongs to $0-1$. If the information is more complete, $p_{i j k}$ is more close to 1 .

If the indicator system has more than several levels, the fuzzy comprehensive evaluation need to be processed according to its levels.

First grade fuzzy comprehensive evaluation:

The first grade fuzzy comprehensive evaluation of one dimension $i$ is:

$G_{i}=w_{i} \times f_{i}=\left(w_{i_{1}}, w_{i_{2}}, \ldots, w_{i_{n}}\right)\left[\begin{array}{ccc}g_{i_{1} 1} & \cdots & g_{i_{1} m} \\ \vdots & \ddots & \vdots \\ g_{i_{n} 1} & \cdots & g_{i_{n} m}\end{array}\right]$

At the same time, other dimensions should also be processed according to the first grade fuzzy comprehensive evaluation. All the results will be used in the second grade fuzzy comprehensive evaluation.

Second grade fuzzy comprehensive evaluation:

The second grade fuzzy comprehensive evaluation is processed on the basis of first grade evaluation and all the result got can be used to evaluate the performance of bank's microfinance. According to the maximum degree of membership principle, the result which has the maximum value is the evaluation result of bank's microfinance.

According to the following formula we can get the second grade fuzzy comprehensive evaluation result:

$$
G=W \times\left(G_{1}, G_{2}, \ldots, G_{N}\right)^{T}=\left(w_{1}, w_{2}, \ldots, w_{N}\right) \times\left(G_{1}, G_{2}, \ldots, G_{N}\right)^{T}
$$

\section{Construction of Performance Evaluation Model}

BSC often evaluates the performance of companies or banks from 4 dimensions which are finance, customer, internal process and learning and growth. However, it does not mean that it only has four dimensions. According to the industry condition and strategy of the company, it is necessary to add one or more new dimensions. Small and micro businesses microfinance is one of the important source of profit of small and medium-sized banks and it is also the social responsibility of banks to support small and micro businesses. Many small and micro businesses are high-tech, clean energy or companies in emerging industry supported by government. It also reflects banks social responsibility by supporting them with financing. Therefore, we designed a BSC performance evaluation model with five dimensions which are finance, customer, internal process, learning and growth and social responsibility.

'Table 1 ' is the performance evaluation model. 
Table 1. Performance Evaluation Model

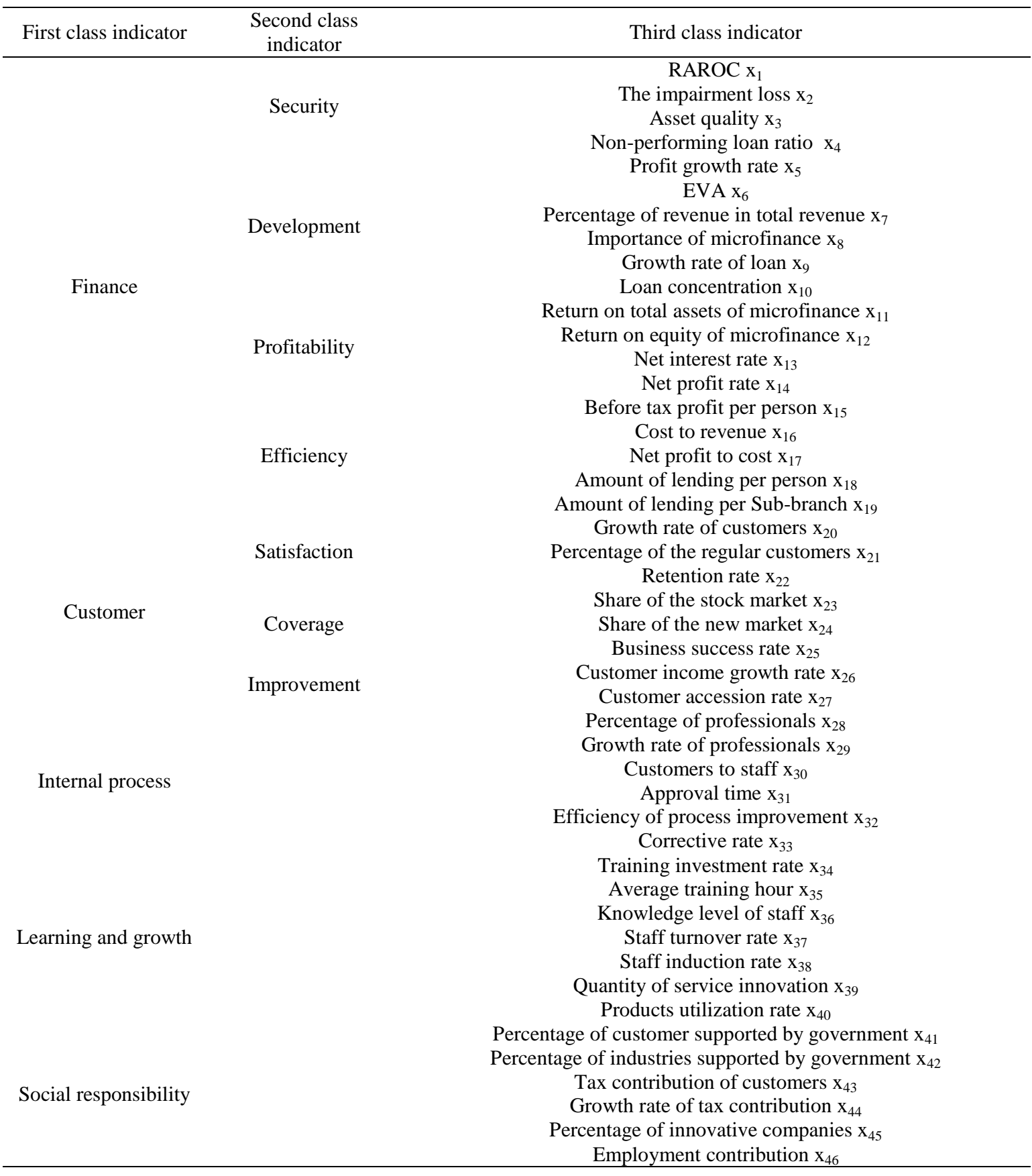

\section{Empitical Research of Fuzzy Performance Evaluation}

Our research object is HARBIN Bank. Microfinance is the most important business and the strategy center. Loan balance of microfinance takes $69.1 \%$ of total loan. Interest income from microfinance is $67.9 \%$ of total customer interest income. Microfinance becomes HARBIN Bank's core business and the number of small and micro businesses microfinance is over 33,000. Our purpose is to establish effective performance evaluation model to evaluate the development of banks' microfinance by empirical analysis of HARBIN Bank and provide information for future development and improvement. 
We invited 13 experts to evaluate the weight and the dot degree of each indicator. After collecting all experts' result, the fuzzy comprehensive matrix of each dimension can be got.

The evaluation result is defined in five grades which are 'excellent', 'every good', 'good', 'common', 'worse'.

The evaluation grade set is:

$M=\left\{m_{1}, m_{2}, m_{3}, m_{4}, m_{5}\right\}=\{$ excellent , very good, good, common, worse $\}$

In the evaluation system, there are five dimensions that affect bank's microfinance, which are finance, customer, internal process, learning and growth and social responsibility. Therefore, the factor set of fuzzy comprehensive evaluation is:

$V=\left\{v_{1}, v_{2}, v_{3}, v_{4}, v_{5}\right\}$

$=\{$ finance, customer, internal process, learning and growth, social responsibi lity $\}$

The weight of five dimensions is:

$W=\left\{w_{1}, w_{2}, w_{3}, w_{4}, w_{5}\right\}=\{0.41,0.24,0.16,0.11,0.08\}$

This paper used the fuzzy comprehensive evaluation method which is based on the rough set to evaluate the microfinance performance of branches of Harbin bank in the year 2013.

\subsection{The Result of First Grade Fuzzy Comprehensive Evaluation}

According to the fuzzy comprehensive evaluation method which is based on the rough, and the data of each branch in year 2013 and the formula (9), each dimension's result of first grade fuzzy comprehensive evaluation is calculated. Therefore, 8 branches' first fuzzy comprehensive evaluation set is shown in the Table 2 to Table 9. 2.

The first fuzzy comprehensive evaluation set of Mudanjiang branch is in the table

Table 2. First-Grade Fuzzy Comprehensive Evaluation Results of Mudanjiang Branch

\begin{tabular}{cccccc}
\hline Dimension & $\mathrm{g}_{1}$ & $\mathrm{~g}_{2}$ & $\mathrm{~g}_{3}$ & $\mathrm{~g}_{4}$ & $\mathrm{~g}_{5}$ \\
\hline Finance & 0.047495 & 0.123548 & 0.103728 & 0.18373 & 0.541499 \\
Customer & 0.427377 & 0.080129 & 0.340498 & 0.151996 & 0 \\
Internal process & 0.326683 & 0.42665 & 0.099613 & 0.096872 & 0.050181 \\
Learning and growth & 0.35 & 0.040909 & 0.149103 & 0.284822 & 0.175166 \\
Social responsibility & 0.4063 & 0.122613 & 0.293421 & 0.177667 & 0 \\
\hline
\end{tabular}

The first fuzzy comprehensive evaluation set of Shuangyashan branch is in Table 3.

Table 3. First-Grade Fuzzy Comprehensive Evaluation Results of Shuangyashan Branch

\begin{tabular}{cccccc}
\hline Dimension & $\mathrm{g}_{1}$ & $\mathrm{~g}_{2}$ & $\mathrm{~g}_{3}$ & $\mathrm{~g}_{4}$ & $\mathrm{~g}_{5}$ \\
\hline Finance & 0 & 0.015195 & 0.190739 & 0.359863 & 0.434203 \\
Customer & 0.419102 & 0.139898 & 0.03 & 0.109318 & 0.301682 \\
Internal process & 0.54 & 0 & 0.30656 & 0.136726 & 0.016714 \\
Learning and growth & 0.467632 & 0.102368 & 0.06 & 0.067669 & 0.302331 \\
Social responsibility & 0.2885 & 0 & 0.1178 & 0.226279 & 0.367421 \\
\hline
\end{tabular}


The first fuzzy comprehensive evaluation set of Shuihua branch is in the Table 4 .

Table 4. First-Grade Fuzzy Comprehensive Evaluation Results of Shuihua Branch

\begin{tabular}{cccccc}
\hline Dimension & $\mathrm{g}_{1}$ & $\mathrm{~g}_{2}$ & $\mathrm{~g}_{3}$ & $\mathrm{~g}_{4}$ & $\mathrm{~g}_{5}$ \\
\hline Finance & 0.204667 & 0.248854 & 0.183733 & 0.264021 & 0.098725 \\
Customer & 0.299172 & 0.489003 & 0.211825 & 0 & 0 \\
Internal process & 0.388157 & 0.411843 & 0.2 & 0 & 0 \\
Learning and growth & 0.35 & 0 & 0.06 & 0.168443 & 0.421557 \\
Social responsibility & 0.24927 & 0.46223 & 0 & 0 & 0.2885 \\
\hline
\end{tabular}

The first fuzzy comprehensive evaluation set of Dalian branch is in the Table 5 .

Table 5. First-Grade Fuzzy Comprehensive Evaluation Results of Dalian Branch

\begin{tabular}{cccccc}
\hline Dimension & $\mathrm{g}_{1}$ & $\mathrm{~g}_{2}$ & $\mathrm{~g}_{3}$ & $\mathrm{~g}_{4}$ & $\mathrm{~g}_{5}$ \\
\hline Finance & 0.463926 & 0.242474 & 0.026747 & 0.169455 & 0.097398 \\
Customer & 0.379 & 0.0075 & 0.212365 & 0.259096 & 0.14204 \\
Internal process & 0.05 & 0.498333 & 0.237291 & 0.214376 & 0 \\
Learning and growth & 0.13 & 0.045652 & 0.064348 & 0.089208 & 0.670792 \\
Social responsibility & 0.587915 & 0.297583 & 0.114502 & 0 & 0 \\
\hline
\end{tabular}

The first fuzzy comprehensive evaluation set of Harbin branch is in the Table 6 .

Table 6. First-Grade Fuzzy Comprehensive Evaluation Results of Harbin Branch

\begin{tabular}{cccccc}
\hline Dimension & $\mathrm{g}_{1}$ & $\mathrm{~g}_{2}$ & $\mathrm{~g}_{3}$ & $\mathrm{~g}_{4}$ & $\mathrm{~g}_{5}$ \\
\hline Finance & 0.269754 & 0.407221 & 0.045624 & 0.037339 & 0.240061 \\
Customer & 0.26629 & 0.1023 & 0.35541 & 0.103923 & 0.172077 \\
Internal process & 0.14 & 0.175 & 0.485489 & 0.089511 & 0.11 \\
Learning and growth & 0.17154 & 0.17846 & 0 & 0.193519 & 0.456481 \\
Social responsibility & 0.352101 & 0.282866 & 0.076533 & 0.118689 & 0.169811 \\
\hline
\end{tabular}

The first fuzzy comprehensive evaluation set of Hegang branch is in the Table 7.

Table 7. First-Grade Fuzzy Comprehensive Evaluation Results of Hegang Branch

\begin{tabular}{cccccc}
\hline Dimension & $\mathrm{g}_{1}$ & $\mathrm{~g}_{2}$ & $\mathrm{~g}_{3}$ & $\mathrm{~g}_{4}$ & $\mathrm{~g}_{5}$ \\
\hline Finance & 0.078478 & 0.14057 & 0.119737 & 0.180719 & 0.480496 \\
Customer & 0.133 & 0.110186 & 0.558065 & 0.18975 & 0.009 \\
Internal process & 0.446667 & 0.093333 & 0.073333 & 0.036667 & 0.35 \\
Learning and growth & 0.052842 & 0.394277 & 0.209093 & 0.241789 & 0.102 \\
Social responsibility & 0.24715 & 0.33545 & 0.07 & 0 & 0.3474 \\
\hline
\end{tabular}

The first fuzzy comprehensive evaluation set of Jixi branch is in the Table 8 . 
Table 8. First-Grade Fuzzy Comprehensive Evaluation Results of Jixi Branch

\begin{tabular}{cccccc}
\hline Dimension & $\mathrm{g}_{1}$ & $\mathrm{~g}_{2}$ & $\mathrm{~g}_{3}$ & $\mathrm{~g}_{4}$ & $\mathrm{~g}_{5}$ \\
\hline Finance & 0.064225 & 0.310502 & 0.226187 & 0.185082 & 0.214004 \\
Customer & 0.366333 & 0.261939 & 0.121589 & 0.031061 & 0.219078 \\
Internal process & 0 & 0 & 0 & 0.915417 & 0.084583 \\
Learning and growth & 0.32875 & 0.222715 & 0.356269 & 0.092266 & 0 \\
Social responsibility & 0.10322 & 0.17098 & 0.2081 & 0.17619 & 0.34151 \\
\hline
\end{tabular}
9.

The first fuzzy comprehensive evaluation set of Shenyang branch is in the Table

Table 9. First-grade Fuzzy Comprehensive Evaluation Results of Shenyang Branch

\begin{tabular}{cccccc}
\hline Dimension & $\mathrm{g}_{1}$ & $\mathrm{~g}_{2}$ & $\mathrm{~g}_{3}$ & $\mathrm{~g}_{4}$ & $\mathrm{~g}_{5}$ \\
\hline Finance & 0.488097 & 0.208956 & 0.117678 & 0.152912 & 0.043557 \\
Customer & 0.101693 & 0.307454 & 0.150687 & 0.300417 & 0.13975 \\
Internal process & 0 & 0.627113 & 0.372887 & 0 & 0 \\
Learning and growth & 0.17 & 0.144586 & 0.154414 & 0.399068 & 0.131932 \\
Social responsibility & 0.327786 & 0.115702 & 0.180512 & 0.19377 & 0.18223 \\
\hline
\end{tabular}

\subsection{The Result of Second Grade Fuzzy Comprehensive Evaluation}

According to the formula (10), we can get the result of second grade fuzzy comprehensive evaluation. Table 10 is the result of 8 branches' second grade fuzzy comprehensive evaluation.

Table 10. Second-Grade Fuzzy Comprehensive Evaluation Results

\begin{tabular}{cccccc}
\hline Branch & $\mathrm{g}_{1}$ & $\mathrm{~g}_{2}$ & $\mathrm{~g}_{3}$ & $\mathrm{~g}_{4}$ & $\mathrm{~g}_{5}$ \\
\hline Mudanjiang & 0.243088 & 0.150245 & 0.181546 & 0.172649 & 0.252473 \\
Shuangyashan & 0.254313 & 0.050194 & 0.149897 & 0.22502 & 0.320577 \\
Shuihua & 0.273419 & 0.325257 & 0.164006 & 0.127733 & 0.109585 \\
Dalian & 0.359221 & 0.209737 & 0.114535 & 0.174431 & 0.142076 \\
Harbin & 0.24705 & 0.265139 & 0.184172 & 0.084084 & 0.219555 \\
Hegang & 0.159408 & 0.169102 & 0.222434 & 0.151121 & 0.297934 \\
Jixi & 0.157059 & 0.230936 & 0.178536 & 0.247585 & 0.185884 \\
Shenyang & 0.275908 & 0.280489 & 0.17321 & 0.193669 & 0.081428 \\
\hline
\end{tabular}

Table 11. Total Variance Explained

\begin{tabular}{|c|c|c|c|c|c|c|}
\hline \multirow{2}{*}{ Component } & \multicolumn{3}{|c|}{ Initial Eigenvalues } & \multicolumn{2}{c|}{ Extraction Sums of Squared Loadings } \\
\cline { 2 - 7 } & Total & \% of Variance & Cumulative \% & Total & \% of Variance & $\begin{array}{c}\text { Cumulative } \\
\%\end{array}$ \\
\hline 1 & 10.375 & 22.554 & 22.554 & 10.375 & 22.554 & 22.554 \\
2 & 9.561 & 20.784 & 43.338 & 9.561 & 20.784 & 43.338 \\
3 & 7.842 & 17.047 & 60.385 & 7.842 & 17.047 & 60.385 \\
4 & 6.561 & 14.264 & 74.649 & 6.561 & 14.264 & 74.649 \\
5 & 5.866 & 12.753 & 87.401 & 5.866 & 12.753 & 87.401 \\
6 & 3.601 & 7.828 & 95.23 & 3.601 & 7.828 & 95.23 \\
7 & 2.194 & 4.77 & 100 & 2.194 & 4.77 & 100 \\
\hline
\end{tabular}


Table 12. Component Score Coefficient Matrix

\begin{tabular}{|c|c|c|c|c|c|}
\hline & \multicolumn{5}{|c|}{ Component } \\
\hline & 1 & 2 & 3 & 4 & 5 \\
\hline Zscore(X1) & 0.053 & -0.057 & -0.061 & -0.019 & 0.063 \\
\hline Zscore(X2) & -0.003 & 0.01 & 0 & 0.151 & 0.012 \\
\hline Zscore(X3) & 0.032 & -0.021 & -0.049 & 0.046 & -0.017 \\
\hline Zscore(X4) & -0.004 & 0.003 & -0.054 & 0.134 & 0.03 \\
\hline Zscore(X5) & -0.069 & -0.003 & 0.033 & 0.03 & 0.1 \\
\hline Zscore(X6) & 0.061 & 0.008 & 0.084 & 0.048 & 0.037 \\
\hline Zscore(X7) & -0.078 & 0.04 & 0.013 & 0.025 & -0.042 \\
\hline Zscore(X8) & 0.057 & 0.081 & -0.012 & 0.005 & 0.019 \\
\hline Zscore(X9) & 0.013 & 0.09 & -0.026 & 0.03 & 0.035 \\
\hline Zscore(X10) & 0.05 & -0.004 & 0.101 & 0.043 & 0.025 \\
\hline Zscore(X11) & 0.072 & 0.024 & 0.002 & -0.052 & -0.01 \\
\hline Zscore(X12) & 0.051 & -0.011 & 0.099 & 0.029 & 0.025 \\
\hline Zscore(X13) & 0.083 & 0.028 & -0.033 & -0.033 & -0.042 \\
\hline Zscore(X14) & 0.087 & -0.01 & 0.003 & 0.042 & 0.015 \\
\hline Zscore(X15) & 0.067 & 0.056 & 0.028 & 0.041 & 0.028 \\
\hline Zscore(X16) & -0.046 & 0.032 & -0.075 & -0.066 & 0.058 \\
\hline Zscore(X17) & 0.011 & 0.049 & -0.057 & -0.101 & 0.008 \\
\hline Zscore(X18) & 0.05 & 0.079 & -0.037 & 0.031 & 0.022 \\
\hline Zscore(X19) & 0.032 & 0.069 & -0.033 & 0.032 & 0.003 \\
\hline Zscore(X20) & -0.013 & 0.099 & -0.008 & -0.019 & 0.036 \\
\hline Zscore $(\mathrm{X} 21)$ & 0.002 & 0.062 & 0.04 & -0.068 & 0.097 \\
\hline Zscore(X22) & 0.004 & 0.079 & -0.04 & -0.061 & 0.052 \\
\hline Zscore(X23) & 0.052 & -0.023 & 0.088 & -0.003 & 0.058 \\
\hline Zscore(X24) & 0.017 & -0.046 & -0.002 & -0.059 & -0.044 \\
\hline Zscore(X25) & -0.04 & 0.061 & 0.036 & 0.085 & -0.048 \\
\hline Zscore(X26) & 0.001 & 0.003 & -0.06 & 0.075 & -0.016 \\
\hline Zscore(X27) & 0.037 & -0.033 & -0.09 & 0.029 & 0.044 \\
\hline Zscore(X28) & -0.077 & 0.03 & 0.022 & -0.045 & 0.006 \\
\hline Zscore(X29) & -0.04 & 0.052 & -0.089 & 0.007 & -0.04 \\
\hline Zscore(X30) & 0.001 & 0.009 & 0.09 & 0.073 & 0.068 \\
\hline Zscore (X31) & -0.064 & 0.028 & 0.007 & 0.042 & -0.099 \\
\hline Zscore(X32) & 0.004 & -0.011 & 0.011 & 0.009 & -0.165 \\
\hline Zscore(X33) & -0.036 & 0.061 & 0.071 & 0.02 & -0.065 \\
\hline Zscore(X34) & 0.018 & -0.065 & -0.059 & -0.029 & 0.094 \\
\hline Zscore(X35) & -0.016 & -0.061 & -0.012 & 0.001 & -0.127 \\
\hline Zscore(X36) & -0.014 & -0.067 & 0.055 & -0.033 & -0.029 \\
\hline Zscore(X37) & 0.055 & 0.024 & -0.015 & -0.045 & -0.104 \\
\hline Zscore(X38) & 0.013 & -0.033 & -0.015 & -0.086 & -0.008 \\
\hline Zscore(X39) & -0.028 & -0.007 & -0.101 & 0.077 & 0 \\
\hline Zscore $(X 40)$ & 0.015 & 0.004 & 0.076 & -0.114 & -0.031 \\
\hline Zscore $(\mathrm{X} 41)$ & 0.011 & 0.047 & 0.061 & 0.004 & -0.111 \\
\hline Zscore(X42) & -0.051 & 0.069 & 0.034 & -0.058 & -0.013 \\
\hline Zscore(X43) & -0.066 & 0.005 & 0.037 & 0.036 & 0.097 \\
\hline Zscore(X44) & 0.068 & 0.052 & -0.002 & 0.011 & -0.041 \\
\hline Zscore(X45) & 0.025 & 0.074 & -0.013 & -0.049 & -0.013 \\
\hline Zscore(X46) & -0.057 & 0 & 0.033 & -0.066 & 0.102 \\
\hline
\end{tabular}

\subsection{Comprehensive Evaluation}

Then we can evaluate comprehensively the performance of small and micro businesses microfinance of 8 branches of HARBIN Bank in 2013. After applying dimensionless method, we get standardized indicators and use the factor analysis 
function of SPSS17.0 to obtain eigenvalue, variance and cumulative variance. 'Table 11 ' is the total variance explained.

According to the result in 'Table 11', the percentage of cumulative variance reaches to $87.401 \%$ which is greater than $80 \%$, when there are 5 condition satisfied eigenvalues. It means that extracting these 5 components from 46 indicators can explain the performance of 8 branches efficiently and the target of dimension reduction is met.

'Table 12 ' is the component score coefficient matrix. We can get the formula of each component by multiplication of coefficient and corresponding indicator and add all together. This formula can be used to evaluate all samples.

According to the component score coefficient matrix, we get the expressions of the 5 components.

$$
\begin{aligned}
& f_{1}=0.053 \times \text { Zscore }\left(X_{1}\right)+\ldots+(-0.057) \times \text { Zscore }\left(X_{46}\right) \\
& f_{2}=(-0.057) \times \text { Zscore }\left(X_{1}\right)+\ldots+0.000 \times \text { Zscore }\left(X_{46}\right) \\
& f_{3}=(-0.061) \times \text { Zscore }\left(X_{1}\right)+\ldots+0.033 \times \text { Zscore }\left(X_{46}\right) \\
& f_{4}=(-0.019) \times \text { Zscore }\left(X_{1}\right)+\ldots+(-0.066) \times \text { Zscore }\left(X_{46}\right) \\
& f_{5}=0.063 \times \text { Zscore }\left(X_{1}\right)+\ldots+0.102 \times \text { Zscore }\left(X_{46}\right)
\end{aligned}
$$

To analyze the performance of 8 branches, the standardized indicators should be substituted into the expression (11) to (15) and the factor score of each component can be calculated. 'Table 13' is the score of five components of each branch.

Table 13. The Factor Score of Five Components

\begin{tabular}{cccccc}
\hline Branch & C1 & C 2 & C 3 & C4 & C5 \\
\hline Mudanjiang & -0.30678 & 0.3474 & 0.59848 & -2.28889 & -0.44792 \\
Shuangyashan & -0.33306 & -1.10776 & 0.0429 & 0.5329 & -1.95682 \\
Suihua & -0.24364 & 0.80285 & -0.72213 & 0.44902 & -0.09517 \\
Dalian & 0.73753 & 1.62392 & -0.58979 & 0.17261 & 0.01111 \\
Harbin & 1.2342 & -0.13525 & 1.95864 & 0.65401 & 0.44266 \\
Hegang & -1.90934 & -0.22783 & 0.43373 & 0.3742 & 1.27786 \\
Jixi & 0.99608 & -1.50342 & -1.22416 & -0.52665 & 1.03107 \\
Shenyang & -0.17499 & 0.20009 & -0.49767 & 0.63282 & -0.2628 \\
\hline
\end{tabular}

To eliminate the influence of subjective factors, we choose objective weight method to calculate the comprehensive score. From 'Table 11', we can get the weight of Component 1 is $22.55 \%$, Component 2 is $20.75 \%$, Component 3 is $17.05 \%$, Component 4 is $14.26 \%$, Component 5 is $12.38 \%$.

We assume that $\mathrm{f} 1, \mathrm{f} 2, \mathrm{f} 3, \mathrm{f} 4$, f5 is the score of each component and $\mathrm{F}$ is the expression of the comprehensive score. The expression is:

$$
F=22.55 \% \times f_{1}+20.75 \% \times f_{2}+17.05 \% \times f_{3}+14.26 \% \times f_{4}+12.38 \% \times f_{5}
$$

The comprehensive score can be calculated by expression (16) and the ranking of the performance evaluation can be also obtained. 'Table 14' is the ranking of performance evaluation. 
Table 14. The Ranking of Performance Evaluation

\begin{tabular}{ccccccc}
\hline Branch & C1 & Ranking & C2 & Ranking & C3 & Ranking \\
\hline Mudanjiang & -0.3067 & 6 & 0.3474 & 3 & 0.59848 & 2 \\
Shuangyashan & -0.3330 & 7 & -1.1077 & 7 & 0.0429 & 4 \\
Suihua & -0.2436 & 5 & 0.8028 & 2 & -0.7221 & 7 \\
Dalian & 0.7375 & 3 & 1.6239 & 1 & -0.5897 & 6 \\
Harbin & 1.2342 & 1 & -0.1352 & 5 & 1.9586 & 1 \\
Hegang & -1.9093 & 8 & -0.2278 & 6 & 0.4337 & 3 \\
Jixi & 0.9960 & 2 & -1.5034 & 8 & -1.2241 & 8 \\
Shenyang & -0.1749 & 4 & 0.2000 & 4 & -0.4976 & 5 \\
\hline Branch & C4 & Ranking & C5 & Ranking & Total score & Ranking \\
\hline Mudanjiang & -2.2888 & 8 & -0.4479 & 7 & -0.2785 & 7 \\
Shuangyashan & 0.5329 & 3 & -1.9568 & 8 & -0.4715 & 8 \\
Suihua & 0.4490 & 4 & -0.0951 & 5 & 0.0407 & 3 \\
Dalian & 0.1726 & 6 & 0.0111 & 4 & 0.4293 & 2 \\
Harbin & 0.6540 & 1 & 0.4426 & 3 & 0.7338 & 1 \\
Hegang & 0.3742 & 5 & 1.2778 & 1 & -0.1877 & 5 \\
Jixi & -0.5266 & 7 & 1.0310 & 2 & -0.2401 & 6 \\
Shenyang & 0.6328 & 2 & -0.2628 & 6 & -0.0259 & 4
\end{tabular}

\subsection{Resultes and Discussion}

From the table 10, we can get the result of 8 branches of Harbin bank. According to the evaluation result set $M=$ \{excellent, very good, good, common, worse $\}$, we can get the performance result of each branch. Based on the maximum membership principle, the performance result of Mudanjian is 'worse', Shuangyashan is 'worse', Shuihua is 'very good', Dalian is 'excellent', Harbin is 'very good', Hegang is 'worse', Jixi is 'common' and Shenyang is 'very good'.

From the finance dimension, Shuangyashan, Mudanjiang, Hegang got a result of 'worse', Shuihua is 'common', Harbin and Jixi are 'very good', and Dalian and Shenyang are 'excellent'. We can get that Dalian and Shenyang has the best performance in finance dimension and Mudanjiang, Shuangyashan, Hegang should improve their performance in finance. The three branches should take actions to improve the security of loan, increase the amount and scope of microfinance loan, do some marketing, reduce general expenses and raise the interest rate.

From the customer dimension, Mudanjiang, Shuangyashan, Dalian, Jixi are 'excellent', Shuihua and Shenyang are 'very good', Harbin and Hegang are 'good'. In general, performance in customer dimension is relative good; however, they still need to take actions to improve customer loyalty, attract new customers and improve the service quality and design customized services.

From the internal process dimension, Mudanjiang, Shuihua, Dalian, Hegang and Shenyang has the result of 'very good', Shuangyashan is 'excellent', Harbin is 'good' and Jixi is 'common'. Jixi should take measures to improve the efficiency of internal process, like improving the professional ability of employees, simplifying the approval process and solving detected problems in time, and so on.

From learning and growth dimension, Mudanjiang and Shuangyashan are 'excellent', Shuihua, Dalian and Harbin are 'worse', Hegang is 'very good', Jixi is 'good' and Shenyang is 'common'. Dalian and Harbin have the poor performance and Shenyang is also not good. Therefore, these branches should invest more on employee training, build a good training system. What's more, they should recruit more specialized employees and design an efficient motivation system.

From the dimension of social responsibility, Mudanjiang, Dalian, Harbin, Shenyang are 'excellent', Shuangyashan, Hegang, Jixi are 'worse', Shuihua is 'very good'. We can find that polarization is very serious. Branches who have poor performance should learn from the good performance branches. Poor branches should provide more financial support to small businesses who can provide more 
jobs and who have strong innovation ability, especially who have independent intellectual property rights. Besides, the support should be the long-term support, not only short-term support.

From the 'Table 14', Harbin branch has the greatest comprehensive score, so its performance evaluation is best. The second to fifth is Dalian, Suihua, Shenyang, Hegang, Jixi and Mudanjiang. Shuangyashan is the last.

\section{Summary}

In this paper, we used the fuzzy comprehensive performance evaluation method which is based on the rough set to evaluate the microfinance performance of branches of Harbin bank. First, we got the result of each dimension according to the first grade fuzzy comprehensive evaluation, and then we got the second evaluation result based on the result of first grade evaluation and weight of dimensions. We assessed the performance of branches of Harbin bank, according these result and analyzed the empirical results from 5 components.

We made suggestions, such as developing new customers, increase the loan to promising and innovative companies, improving the efficiency of business process and increasing the investment in staff training, to the branches who performed worst in each component based on the analysis results.

Our search method and conclusions can provide useful suggestions to improve the performance of small and micro businesses microfinance for Chinese commercial banks.

\section{References}

[1] K. S. Adesina, "A comparative performance evaluation of the Nigerian banking sector in the post 2005 consolidation: through the camel rating system", International Journal of Business Social Science, no. 13, (2012), pp. 259-268.

[2] T. R. Gebba and I. E. Ahmed, "The performance of privatized financial institutions in Egypt: the case of Alexandria bank", Journal of Applied Finance Bank, no. 3, (2013), pp. 245-269.

[3] S. Canbas, A. Cabuk and S. B. Kilic, "Prediction of commercial bank failure via multivariate statistical analysis of financial structures: the Turkish case", European Journal of Operational Research, vol. 166, (2005), pp. 528-546.

[4] M. P. Amiri and A. P. Amiri, "An analytical network process approach for evaluating banking performance based on balanced scorecard", Trends Applied Science Research, no. 6, (2012), pp. 456466.

[5] J. Jablonsky, P. Fiala, Y. Smirlis and D. K. Despotis, "DEA with interval data: an illustration using the eEvaluation of branches of a Czech bank", Central European Journal of Operational Research, no. 4, (2004), pp. 323-337.

[6] I. E. Tsolas and D. I. Giokas, "Bank branch efficiency evaluation by means of least absolute deviations and DEA", Management Finance, no. 8, (2012), pp. 768-785.

[7] M. R. Bhuia, A. Baten, A. A. Kamil and N. Deb, "Evaluation of online bank efficiency in Bangladesh: a data envelopment analysis (DEA) approach", Journal of Internet Bank Commerce, no. 17, (2012), pp. $1-17$.

[8] K. S. Thagunna and S. Poudel, "Measuring bank performance of Nepali banks: a data envelopment analysis (DEA) perspective", International Journal of Economics and Financial Issues, (2013), no. 1, pp. 54-65.

[9] S. A. Rahim, “An Analysis of Performance Appraisal System of Mercantile Bank Limited”, The Academy of Business and Retail Management (ABRM), London, (2012), pp. 27-35. 